\title{
Correction to: System Engineering a Solar Thermal Propulsion Mission Concept for Rapid Interstellar Medium Access
}

\author{
Jonathan Sauder ${ }^{1}$ (D) Michael Preudhomme ${ }^{1}$. Juergen Mueller ${ }^{1} \cdot$ Dean Cheikh $^{1}$ - Eric Sunada ${ }^{1} \cdot$ Reza R. Karimi $^{1}$. \\ Abigail Couto $^{1} \cdot$ Nitin Arora $^{2} \cdot$ Jacqueline Rapinchuk $^{1} \cdot$ Leon Alkalai $^{3}$
}

Published online: 27 August 2021

(c) California Institute of Technology and its operating division, the Jet Propulsion Laboratory, under exclusive license to Chinese Society of Astronautics and Springer Nature Singapore Pte Ltd 2021

\section{Correction to: \\ Advances in Astronautics Science and Technology https://doi.org/10.1007/s42423-021-00077-2}

This article was published online first on 27. July 2021 under the title mentioned above. After this publication, the Author has asked to remove the "For the 71st IAC" at the beginning of the article title so that it should read "System Engineering a Solar Thermal Propulsion Mission Concept for Rapid Interstellar Medium Access".

The original article has been corrected.
The original article can be found online at https://doi.org/10.1007/ s42423-021-00077-2.

Jonathan Sauder

jsauder@jpl.nasa.gov

Michael Preudhomme

Michael.Preudhomme@jpl.nasa.gov

Juergen Mueller

Juergen.Mueller@jpl.nasa.gov

Dean Cheikh

Dean.A.Cheikh@jpl.nasa.gov

Eric Sunada

Eric.T.Sunada@jpl.nasa.gov

Reza R. Karimi

Reza.R.Karimi@jpl.nasa.gov

Abigail Couto

Abigail.r.Couto@jpl.nasa.gov

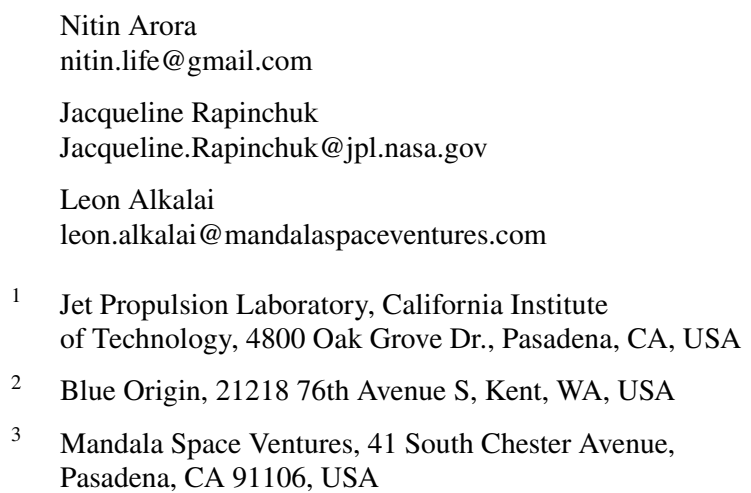

